\title{
Mangrove increases resiliency of the French Guiana shrimp fishery facing global warming
}

\author{
Diop Bassirou ${ }^{1,{ }^{*}}$, Blanchard Fabian ${ }^{2}$, Sanz Nicolas ${ }^{3}$
}

${ }^{1}$ CNRS, UMRS 3456, LEEISA, Domaine de Suzini, BP 477, 97337 Cayenne, French Guiana

2 Ifremer, UMRS 3456, LEEISA, Domaine de Suzini, BP 477, 97331 Cayenne, French Guiana

${ }^{3}$ Université de Guyane, UMRS 3456, LEEISA, Campus Troubiran BP 20792, 97337 Cayenne, French Guiana

* Corresponding author : Bassirou Diop, email address : bassirou.diop@univ-guyane.fr

\begin{abstract}
:
This paper deals with the biological, ecological and economic impact of global warming and mangrove habitat availability on the French Guiana shrimp fishery. A dynamic bio-economic model is built by employing a shrimp stock's growth function depending on Sea Surface Temperature (SST) and on mangrove surface. The model is empirically calibrated for the French Guiana shrimp fishery using time series collected over 1995-2011. First, two Cobb-Douglas functions, which describe shrimp's natural growth and harvest, are estimated. Then, a Maximum Economic Yield (MEY) harvest rule, based on the optimization of the net present value derived from fishing, is computed. Three management strategies are compared (Closure, Status Quo management, and MEY) under three mangrove surface fluctuations and climatic scenarios: (a) SST and mangrove remain stable, (b) SST rises while mangrove declines, (c) SST rises and mangrove remains stable. The scenarios considering a SST rise are based on the median greenhouse gases emission projections estimated by the IPCC (Intergovernmental Panel on Climate Change). The scenario focused on the reduction of mangrove surface is based on a general rate calculated on a global level. Our study shows that preserving the mangrove will increase the resiliency of French Guiana shrimp fishery in the long run.
\end{abstract}

\section{Highlights}

A dynamic bio-economic model for French Guiana shrimp fisheries. The model depends on SST and mangrove surface. Closure, Status Quo management, and MEY strategies are considered. Results shows that preserving mangrove will increase the resiliency of the fishery.

Keywords : Renewable resources, Fishery bio-economic model, Global warming, Shrimp, Sea surface temperature, Mangrove

JEL classification Q22 


\section{Introduction}

Shrimp fishery constitutes a major source of value for French Guiana, where it represents the third export sector accounting for $25 \%$ of the total volume (Garandeau, 2006). However, French Guiana shrimp fishery (FGSF) has faced many difficulties during the last decades. Several factors can explain the recent economic crisis; the globalization of the shrimp market led to a decrease of $50 \%$ in real prices since 1997, fuel prices increased worldwide and the 2007 financial crisis also affected the activity. In response to this situation, some management rules were progressively adopted or reinforced in French Guiana, starting with the creation of the Exclusive Economic Zone (EEZ) in 1977 (Smith, 1986). In 1983 a Total Allowable Catch (TAC) system was implemented for both brown and pink shrimps and trawling activities were forbidden in specific coastal zones. However, despite the substantial reduction in fishing effort and harvest levels, the shrimp stock kept decreasing between 1995 and 2011, as depicted in Figure 1, according to data collected by Ifremer (French institute of research for the exploitation of the sea). This suggests that other factors may have a stronger influence on the evolution of the FGSF. River flow rate, Niño/Niña phenomena and sea surface temperature (SST) has been shown as the more important factors negatively affecting the productivity of FGSF (Diop et al., 2018; Sanz et al., 2017). The SST has increased between 1970 and 2004 on the Guiana coast. The difference between the average values of these two periods is $0.65^{\circ} \mathrm{C}$ (degree Celsius), with an accentuation of this phenomenon by 1995 (Bernard, 2006). Moreover, water quality and ecosystems along the French Guiana coast are also strongly influenced by mud banks dynamics dictated by the Amazon River (Anthony et al., 2010). Mud banks are rapidly and massively colonized by mangroves, resulting in a coast partly covered by fluctuating mangrove surfaces (Walcker et al., 2015). In French Guiana, mangroves stretch for $600 \mathrm{~km}^{2}$ and colonize almost $75 \%$ of the coastline (Day Jr et al., 1987; Walcker et al., 2015). Mangroves provide several ecosystem services such as carbon sink, nursery, shoreline protection against erosion and play a critical role in the ecological balance (Barbier, 2016). Several small scale studies suggest that mangrove habitats could enhance fish abundances by providing nursery grounds (Serafy et al., 2015). Mangrove forests cover more than $200,000 \mathrm{~km}^{2}$ of sheltered tropical and subtropical coastlines but they are strongly impacted by human activities. Mangrove deforestation is occurring at a rate of 1-2\% per year worldwide and climate change is importantly affecting those habitats (Duke et al., 2007).

Shifts in rainfalls regimes can lead to changes in detritus availability in estuarine and coastal areas. A reduction in detritus have negative effects on penaeid shrimps since they are mostly detritivorous during the juvenile stages (Nunes et al., 1997). Changes in the community structure and increase of predators (red snapper) has been estimated to potentially cause a decrease in shrimps biomass (Lampert, 2011). Most penaeid shrimps have a juvenile stage in estuarine waters followed by a marine adult stage. Therefore, physiological adaptations to strong environmental changes are fundamental for the sur- 
vival of the juveniles to adult stage (Silva et al., 2010). Despite temperature, which is widely known to be the more important factor for development and growth, previous studies on Farfantepenaeus species suggest that salinity may be more important in regulating survival (Pérez-Castañeda and Defeo, 2005). It is likely that pink and brown shrimps have developed slightly different physiological limits and growth optimum, unfortunately, a comparative study between this two species is still lacking. In French Guiana the impact of human development and sediment dynamics has not been quantified yet but it will surely have an important effect on mangroves habitats and coastal communities. It is therefore crucial to investigate the effect of mangrove fluctuation on FGSF.

Until now, a majority of existing bioeconomic models still assume that environmental conditions in the marine ecosystem remain constant over time, which rarely occurs, as underlined by Knowler (2002). Such an assumption often leads to the misspecification of harvest controls, contributing to the diminished state of many exploited living marine resources (Keyl and Wolff, 2008; Stock et al., 2011). Moreover, a growing number of studies identified a strong response of marine resources to climate variability in recent years e.g. Lehodey et al. (2006). Fishing industries are indeed strongly dependent of natural environmental conditions (Hannesson, 2006). Climate change, and global warming in particular, through its effect on the sea temperature, are important drivers of shrimp stock dynamics and harvest levels (Cheung et al., 2009; Brander, 2007). The accumulating evidences of the effect of anthropogenic emissions on climate change and the rapid and persistent rise in temperatures suggests that temperatures will continue to increase during the next decade (Brander, 2010; Levitus et al., 2000). There is therefore a need to account systematically for this phenomenon in the building process of bioeconomic models. The application of an ecosystem based fisheries management approach accounting simultaneously for the local economic context and environmental trends is probably a more efficient management option for FGSF (Doyen et al., 2013; Thébaud et al., 2014).

The aim of this paper is thus to investigate the simultaneous effects of global warming as well as the role of mangrove fluctuations on the FGSF during the next decades. In order to do so, we develop an extension of the bio-economic model proposed by GarzaGil et al. (2011) and apply the latter to the French Guiana case. The introduction of the SST variable into the growth function allows for a direct evaluation of the impact of global warming on the stock dynamics and thus on the bio-economic equilibrium of the fishery ${ }^{1}$. In our study, we introduce mangrove surface as an additional variable into the analysis to evaluate simultaneously the effect of the changes in SST and mangrove surface variability on the FGSF. A Maximum Economic Yield (MEY) harvest

\footnotetext{
${ }^{1}$ The temperature of waters may be considered as a general proxy of global warming in a first step; the approach used here refers to the Extended Stock Assessment Models (ESAMs; see Stock et al. (2011))
} 
rule, based on the optimization of the net present value derived from fishing, is determined and calibrated using Ifremer data. Then, three different management strategies ("Status Quo", Maximum Economic Yield-"MEY", and "Closure") and three climate and mangrove fluctuation scenarios are compared for the period between 2012 and 2050.

The paper is organized as follows. Section 2 describes the FGSF. Section 3 presents the bio-economic model used to determine the optimal stock, harvest and profit levels that the FGSF would reach in the future if it was managed in a centralized manner under three distinct management strategies, and under three distinct scenarios regarding the trend of the SST and the mangrove surface. Section 4 states and interprets the results of the simulations for the period 2012-2050. Section 5 discusses the results and policy implications. Section 6 gives some concluding remarks.

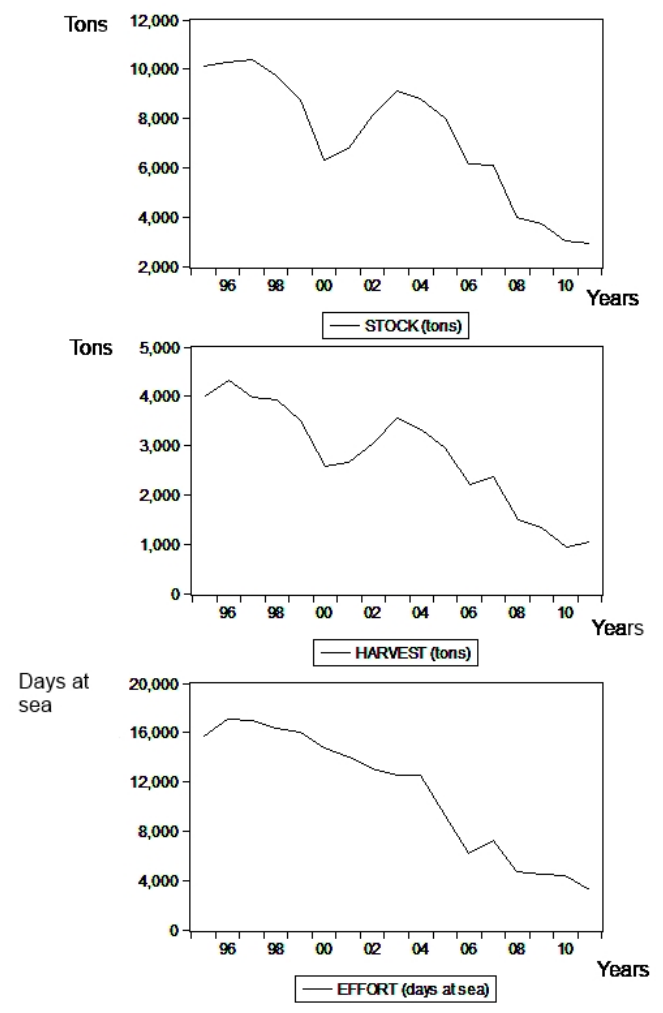

Figure 1: Historical paths of the shrimp stock, fishing effort and harvest levels in French Guiana between 1995-2011 


\section{The French Guiana shrimp fishery}

Two shrimp species are mainly exploited by the French Guiana fishery, the brown and the pink shrimps (resp. Farfantepenaeus subtilis and Farfantepenaeus brasiliensis). The FGSF started in the late 1960's with the US fleet activity. Most of the vessels were Floridian shrimp trawlers, each using two trawls simultaneously. Japanese vessels also exploited shrimps, but the whole fleet became progressively French between 1970 and 1990. Over this period, the US-Japanese fleet increased to up to 80 trawlers. Since 1992, the whole fleet is composed only by French trawlers targeting shrimps on the continental shelf. The stock assessment has been firstly performed every two years by a working group within the institutional and international framework of the Western Central Atlantic Fishery Commission (WECAFC) up to 1999. It has then been undertaken by the Ifremer for management advice since the 1980's. The method used for assessment is the "Virtual Population Analysis" (VPA), that is performed on a monthly basis to enable recruitment and abundance as well as spawning stock biomass and fishing mortality to be determined.

Table 3 (see Appendices) shows time series of the shrimp biomass, catches, effort and SST for the period 1995-2011 obtained from respectively VPA, declarations, and Reynolds data set. The biomass has steadily decreased over the years together with the fishing effort and catch levels (see Figure 1) despite the establishment of a TAC. A TAC of 4180 tons was defined from the Maximum Sustainable Yield (MSY) for brown and pink shrimps of which 108 tons are reserved to neighboring countries (Suriname, Trinidad, Barbados). Compared to historical catches, the TAC level was never fully achieved. This TAC level was never changed until 2011, despite the decreasing trends in biomass and landings. In 1991, a fee-free license system was introduced for both species. The main objective was to limit the number of vessels to protect the shrimp resource. However, the license system did not seem to be an efficient resource management tool. The number of licenses was slightly reduced from 69 in 1991 to 63 in 1999, and to 49 in 2010. During this period, the number of active shrimp trawlers was less than the number of licenses (less than half in 2006). The license system could have been a tool to adjust the number of vessels in order to improve economic results, but this objective was not explicitly addressed by the management system. More recently, some depth restrictions were also put in place in order to limit the impact of trawling on juvenile shrimps and avoid conflicts with the coastal small-scale fishery. Trawling is forbidden in coastal waters less than 30 meters deep. This rule is more restrictive than the spatial limitation applied to trawlers in European waters. Overall, the economic dynamics of the fishery has been characterized by a diminution of the fleet size, to concentrate the fishing activities over a reduced number of profitable vessels (around 10). 


\section{The bio-economic model}

This section presents the bioeconomic model for the FGSF. First, the shrimp's natural growth function and its calibration with a data set covering the period 1995-2011 are presented, followed by the fishery production function and its calibration with a 19952011 time series. Then, the different management strategies of the fishery, and the climate and mangrove evolution scenarios are introduced (see Figure 2).

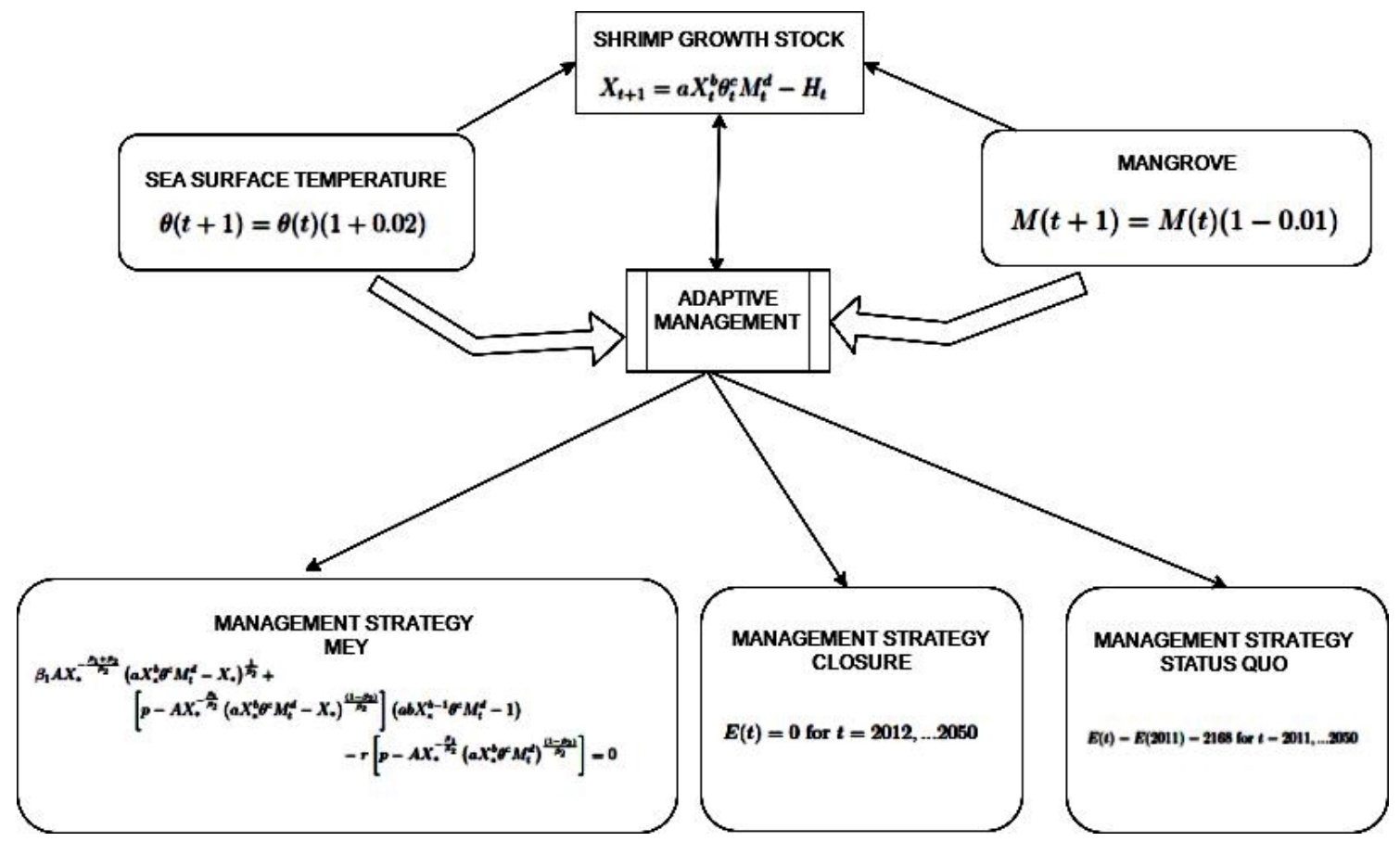

Figure 2: Conceptual diagram of the model. See text for definitions and notations

\subsection{The natural growth functions}

Before studying the effects of SST fluctuations of and mangrove surface on the shrimp stock, harvest, and profits, we have to represent and quantify the renewal of the shrimp using data of the French Guiana collected by Ifremer. We therefore firstly estimated four population dynamics that explicitly integrate SST and mangrove surface. The logistic function is the most widely used in the economic literature. However, other functions may also be used when the logistic model results in non-significant parameters (Bjørndal, 1988; Clark, 1990; Opsomer and Conrad, 1994; Garza-Gil, 1998; Hannesson, 2006; Nøstbakken, 2008; De Lara and Doyen, 2008):

$$
X_{t+1}=a X_{t}+b X_{t}^{2}+c \theta_{t}+d M_{t}-H_{t}
$$


Table 1: Estimates of the Cobb-Douglas natural growth function

\begin{tabular}{lc}
\hline \hline & $X_{t+1}+h_{t}=a X_{t}^{b} \theta_{t}^{c} M^{d}$ \\
$\ln (a)$ & $1.10(0.000)^{* *}$ \\
$b$ & $-11.15(0.0195)^{* *}$ \\
$c$ & $0.10(0.0615)^{*}$ \\
$\mathrm{~d}$ & 0.96 \\
$R^{2}{ }_{\text {adjusted }}$ & 1.96 \\
DW & 0.121 \\
Standard Error of regression & 2.92 \\
JB & 8.92 \\
Q-Stat & \\
\hline Notes: p-values in brackets; ${ }^{* *}{ }_{\text {significant at } 5 \% \text { level }}{ }_{\text {significant at } 10 \% .}$ \\
JB is the Jarque-Bera statistic of the normality test; \\
Q-Stat is the Ljung-Box statistic used in the correlation test; \\
\\
$X_{t+1}=a X_{t} e^{b X_{t}+c \theta_{t} d M_{t}}-H_{t}$ \\
$X_{t+1}=a X_{t}^{b} \theta_{t}^{c} M_{t}^{d}-H_{t}$ \\
$X_{t+1}=a X_{t}^{b+c \theta_{t} d M_{t}}-H_{t}$
\end{tabular}

The above four functional forms are known as the logistic, the Ricker, the Cobb-Douglas, and the Cushing natural growth functions, respectively. The variable $X$ denotes the fish stock biomass, $t$, the time (in year), $H$ the harvest, $a, b, c$, and $d$ the parameters that represent biological and environmental impacts, $\theta$, the SST and $M$ the mangrove surface. The mangrove surface series has been differentiated twice to be stationary and integrated into the regression. The estimation of the parameters of the four natural growth functions using the data shown in Table 3 (see Appendices) and their comparison in statistical terms indicate that, as far as the FGSF is concerned, the Cobb-Douglas relationship is the functional form that best fits the empirical data over the period (1995-2011). The results for the Cobb-Douglas function are presented in Table 1, for which all parameters are significant.

The parameters of the three other functions appear not to be significant and the results of their estimation are reported in Table 4 (see Appendices). The Cobb-Douglas function will thus be used to describe the dynamics of the shrimp stock in the remainder of the paper. 


\subsection{The production function}

Usually, the production function used in bio-economic literature for fisheries is the socalled Schaefer model where catches depend linearly on both fishing effort and stock. Here we depart from the usual approach by considering the Cobb-Douglas form as in Clark (1990) and Sanz et al. (2017):

$$
H_{t}=\alpha X_{t}^{\beta_{1}} E_{t}^{\beta_{2}}
$$

where $\alpha$ denotes catchability, coefficients $\beta_{1}$ and $\beta_{2}$ represent respectively the elasticities of the catch level, $H_{t}$, with respect to the biomass, $X_{t}$, and the effort level, $E_{t}$. The effort level corresponds to the total number of days during which the fleet is at sea. It includes the traveling time to the area where fishing activities take place. Table 2 presents the estimates of the parameters of Equation (5) regarding the FGSF.

Table 2: Estimates of the shrimp production function

\begin{tabular}{lc}
\hline \hline & $\mathrm{H}_{t}=\alpha \mathrm{x}_{t}^{\beta_{1}} \mathrm{E}_{t}^{\beta_{2}}$ \\
$\ln (\alpha)$ & $-2.15(0.000)$ \\
$\beta_{1}$ & $0.95(0.000)$ \\
$\beta_{2}$ & $0.16(0.001)$ \\
$\mathrm{R}^{2}=0.986$ & 0.986 \\
$\mathrm{R}^{2}$ adjusted $=0.984$ & 0.984 \\
Standard Error of regression & 0.069 \\
F-Stat & 541.56 \\
DW & 2.05 \\
JB & 1.36 \\
\hline Notes: p-values in brackets; all coefficients are significant at the $5 \%$ level. \\
F-Stat and DW are respectively the Fisher and the Durbin-Watson statistics; \\
JB is the Jarque-Bera statistic of the normality test.
\end{tabular}

The major statement is that the elasticity of harvest with respect to the stock is very close to $1\left(\beta_{1}=0.95\right)$, making production more sensitive to the stock as compared to fishing effort $\left(\beta_{2}=0.16\right)$. The accuracy of the regression is shown in Figure 8 (see appendices), where we can compare the evolutions between observed and adjusted values of catch.

\subsection{Fishery management}

The model is now calibrated from historical data. We first focus on different fishing strategies at the time horizon $\mathrm{t}=2050$. 


\subsubsection{The MEY strategy}

Here we investigate the management strategy based on the intertemporal optimization of the profit derived from fishing in accordance with the MEY (maximum economic yield) strategy, as in Clark (1990), and Doyen et al. (2013). It relates to a situation where the fishery is rationally managed in a centralized manner or with a sole owner. In more mathematical terms, the economic problem of the regulator consists in choosing catches that maximize the current value of the profit flow, $p H_{t}-w E_{t}$, generated by the production of shrimp, where $p$, and $w$, represent respectively the unit price of harvest, the cost of effort at time $t$. The regulator's bio-economic program can thus be written as:

$$
\begin{array}{ll} 
& \operatorname{Max}_{H_{t}} \sum^{\infty} \delta^{t}\left(p \alpha X_{t}^{\beta_{1}} E_{t}^{\beta_{2}}-w E_{t}\right) \\
\text { st: } \quad & X_{t+1}=a X_{t}^{b} \theta_{t}^{c} M_{t}^{d}-H_{t} \\
0 \leq \quad & X_{t}, 0 \leq E_{t}, X_{0} \text { given } \\
0 \leq & H_{t} \leq \alpha X_{t}^{\beta_{1}} E_{t}^{\beta_{2}}
\end{array}
$$

where $r=(1-\delta) / \delta$ stands for the discount rate, and $\delta$ the discount factor.

The solution of the above problem requires the use of optimum control theory (Kamien and Schwartz, 1991). Assuming that the temperature $\theta$, and the mangrove surface $M$ are at equilibrium, it can be proved that the long-term balance in the renewable resource framework gives the optimal value of the shrimp biomass implicitly as follows (Conrad, 1999; De Lara and Doyen, 2008):

$$
\begin{aligned}
\beta_{1} A X_{*}^{-\frac{\beta_{1}+\beta_{2}}{\beta_{2}}}\left(a X_{*}^{b} \theta^{c} M_{t}^{d}-X_{*}\right)^{\frac{1}{\beta_{2}}}+ & \\
& {\left[p-A X_{*}^{-\frac{\beta_{1}}{\beta_{2}}}\left(a X_{*}^{b} \theta^{c} M_{t}^{d}-X_{*}\right)^{\frac{\left(1-\beta_{2}\right)}{\beta_{2}}}\right]\left(a b X_{*}^{b-1} \theta^{c} M_{t}^{d}-1\right) } \\
& -r\left[p-A X_{*}^{-\frac{\beta_{1}}{\beta_{2}}}\left(a X_{*}^{b} \theta^{c} M_{t}^{d}\right)^{\frac{\left(1-\beta_{2}\right)}{\beta_{2}}}\right]=0
\end{aligned}
$$

where $A=\frac{w}{\alpha^{\frac{1}{\beta_{2}}} \beta_{2}}$. We observe that the optimal value of the shrimp biomass, $X_{*}$, depends on both SST and, mangrove surface and thus we will hereafter denote this optimal biomass level, $X_{*}(\theta, M)$. The optimal harvest rule can then be deduced from the biological dynamics given by Equation (3):

$$
H_{*}(\theta, M)=F\left[X_{*}(\theta, M), \theta\right]-X_{*}(\theta, M)
$$

where $F$ represents the natural growth function. Finally, the effort level can be obtained from the technological constraint, Equation (5):

$$
E_{*}(\theta, M)=\left[\frac{\alpha X_{*}(\theta, M)^{\beta_{1}}}{H_{*}(\theta, M)}\right]^{1 / \beta_{2}}
$$


Regarding the numerical values based on the French Guiana case study, the unit price of landings, $p$, is set to $6.60 € / \mathrm{kg}$, while the cost per unit of effort, $w$, is 1900 $€ /$ day, which corresponds to the mean cost per day at sea. The discount rate equals $r=3 \%$.

\subsubsection{Other management strategies}

We will compare the MEY-type strategy defined previously with two other fishing patterns. The first one termed Status Quo consists in maintaining the fishing effort at its current level (see Table 3 in Appendices), namely:

$$
E(t)=E(2011)=2168 \text { for } t=2011, \ldots 2050
$$

The second pattern, denoted by Closure, relates to a ban for this shrimp fishery, namely:

$$
E(t)=0 \text { for } t=2012, \ldots 2050
$$

\subsection{Climate and mangrove scenarios}

Earth's surface temperature during the last three decade has been increasingly warmer than any previous decade since 1850. The globally averaged and combined land and ocean surface temperatures show a warming of $0.85[0.65 \text { to } 1.06]^{\circ} \mathrm{C}$ over the period 1880 2012 (Intergovernmental Panel on Climate Change-IPCC, 2014). In order to investigate the potential effects of global warming combined with mangrove fluctuations on the FGSF between 2012 and 2050, we selected a single climate scenario of the IPCC, RCP (Representative Concentration Pathway) 4.5, that varies across different intensities of global warming. RCP4.5 (Thomson et al., 2011) corresponds to the pathway with the median greenhouse gas emission levels of the IPCC, and assumes a rise in temperature at the same rate of about $0.02{ }^{\circ} \mathrm{C}$ per year. $\mathrm{RCP} 4.5$ is a scenario of long-term, global emissions of greenhouse gases, short-lived species, and land-use-land cover that stabilizes radiative forcing. The defining characteristics of this scenario are enumerated in Moss et al. (2010). In addition to the global warming scenario, two mangrove fluctuation scenarios are investigated. The first scenario describes a situation where the mangrove surface remains stable at the value observed in $2011\left(519 \mathrm{Km}^{2}\right)$ and the second describes a situation where the mangrove surface declines at the same rate $1 \%$ per year worldwide (FAO, 2007; Spalding, 2010) until 2050. Globally, between $20 \%$ and 35\% of mangrove area has been lost since approximately 1980, and mangrove areas are disappearing at the rate of approximately $1 \%$ per year, with other estimates as high as $2-8 \%$ per year. We thus retain three situations considering SST and mangrove surface: a) SST and mangrove surface will remain stable, b) SST rises and mangrove surface declines at $1 \%$ per year until time horizon 2050, c) SST rises and mangrove remains stable until 2050. 
The following expression describes the evolution of the SST in our analysis:

$$
\theta(t+1)=\theta(t)(1+0.02)
$$

where $\theta(2011)=28.15{ }^{\circ} \mathrm{C}$ corresponds to the temperature value observed in 2011 . And the evolution of the mangrove surface is described by the following expression:

$$
M(t+1)=M(t)(1-0.01)
$$

where $M(2011)=519 \mathrm{Km}^{2}$ corresponds to the mangrove surface observed in 2011 .

\section{Simulations and results}

We can now use the estimates of the natural growth and production functions to simulate the evolutions of the stock, harvest, and profit levels between 2012 and 2050, depending on the climate and mangrove fluctuation scenarios retained and the management strategy adopted. The successful CUSUM (Cumulative Sum) test (Brown et al., 1975), based on the cumulative sum of the recursive residuals, ensures the stability of the parameters over the period 1995-2011 in the Cobb-Douglas function case, allowing for robust forecasts over the period 2012-2050 (see Figure 8 in Appendices). Numerical computations are performed with the software SCILAB 5.4.02. The strategies regarding the shrimp stock, effort, harvest and profit are drawn in Figure 3, 4, 5 and 6 respectively. We present first the management outcomes and in a second time, the economic gains of the MEY fishing strategy.

\subsection{Management outcomes}

As can be seen in Figure 3, when temperature and mangrove remain stable, the biomass recovers with the closure strategy and stabilizes with the MEY and the Status quo ones. On the other side, shrimps biomass depletes if we consider both scenarios where temperature rises and mangrove declines and where temperature rises and mangrove remains stable. Shrimps biomass depletion is mitigated when mangrove surface remains stable and the MEY strategy allows for a better biomass recovery in comparison with the Status Quo strategy. Figure 4 shows that Status Quo effort levels are higher than the MEY effort levels whatever the scenario we consider. This suggests that the level of effort in the Status Quo strategy is too high to expect a better resource preservation. Figure 5 confirms that the MEY strategy is better than the Status Quo since, in the long term, catches are greater for MEY independently of the climate and mangrove scenarios. Figure 6 shows that profits are jeopardized and decline in the long run,

\footnotetext{
${ }^{2}$ SCILAB (http://www.scilab.org) is an open-source software program dedicated to scientific calculus and well suited to the simulation of dynamic systems.
} 
whatever the management strategy adopted. The Status Quo fishing strategy, which consists in maintaining the fishing effort intensity observed in 2011, yields the worst effects on the fishery, since it never allows for the recovery of the stock and leads to a fall in catch and negative profits around 2030. With the MEY strategy, the stock decreases less rapidly and catches are higher than with the Status Quo strategy, making profits remain positive over the whole projection period, even if they tend to zero from around 2050 .

As illustrated in Figures 3, 4, 5, 6, the scenario with stable temperature and mangrove surface appears logically to be less detrimental to the FGSF, but it is still preoccupying from an economical point of view. Globally, the evolutions of the stock, catch and profits are the same. However, the biomass still depletes totally with the Status Quo strategy and almost totally with the MEY strategy.
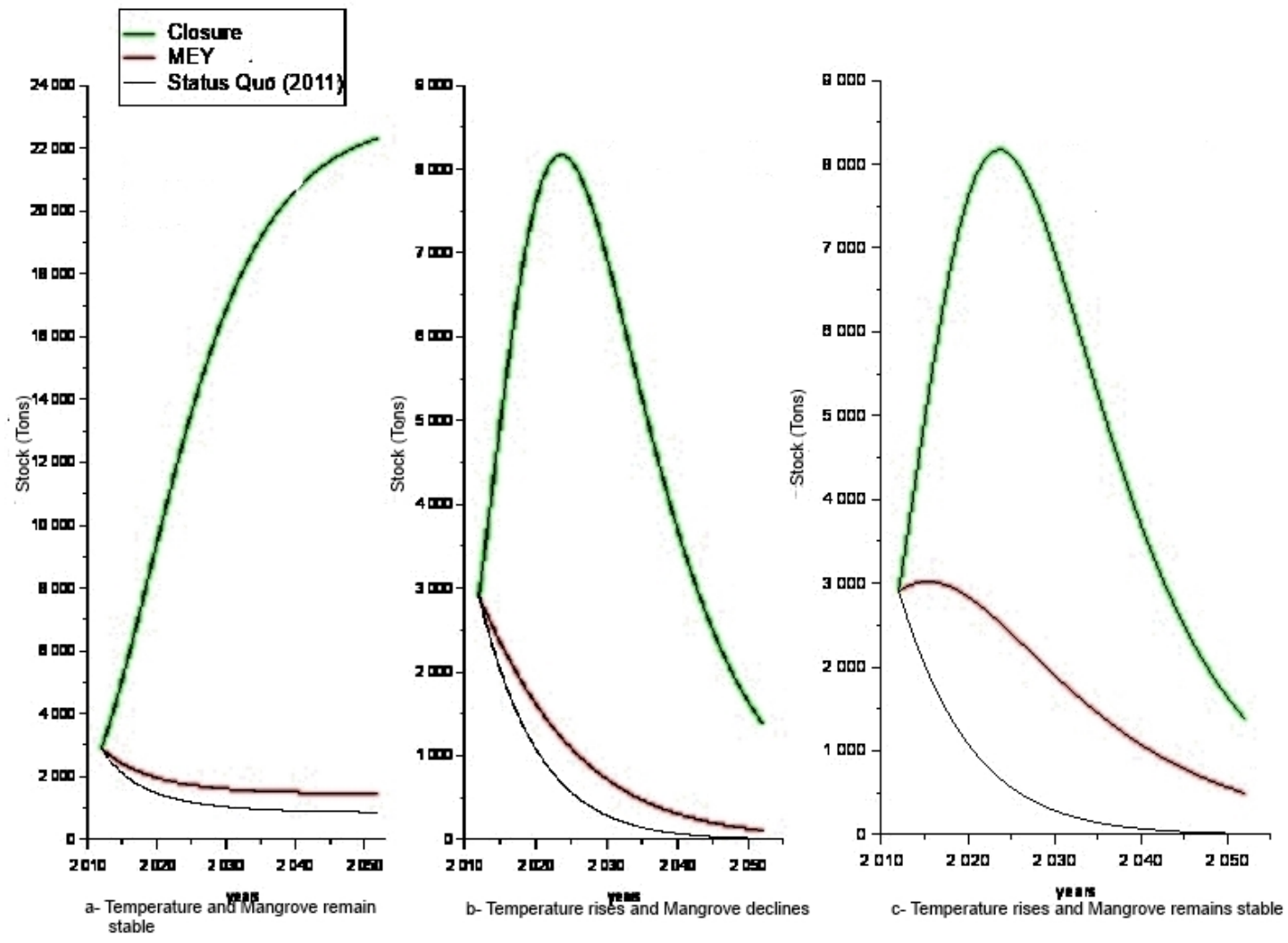

Figure 3: Trajectories for stock under mangrove fluctuations and climatic scenarios: aTemperature and Mangrove remain stable, b- Temperature rises and Mangrove declines, c- Temperature rises and Mangrove remains stable, and under fishing strategies: Closure, MEY and Status Quo 

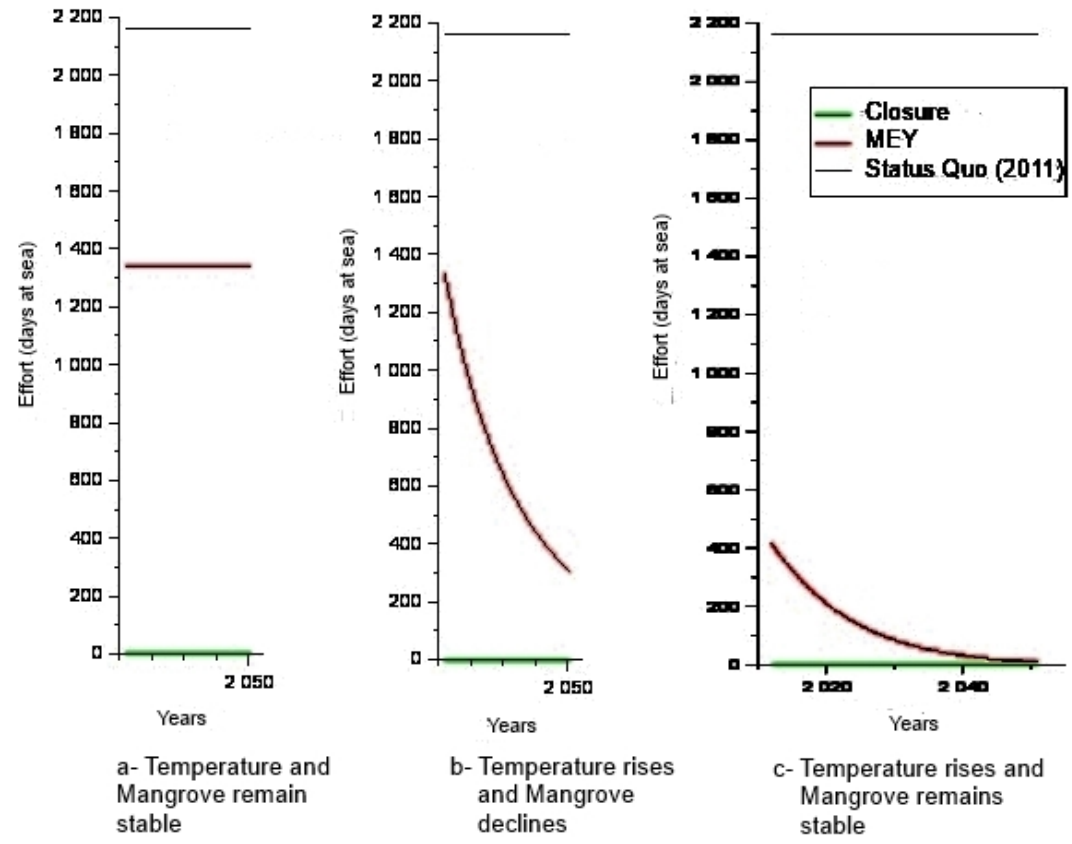

Figure 4: Trajectories for effort under mangrove fluctuations and climatic scenarios: aTemperature and Mangrove remain stable, b- Temperature rises and Mangrove declines, c- Temperature rises and Mangrove remains stable, and under fishing strategies: Closure, MEY and Status Quo 

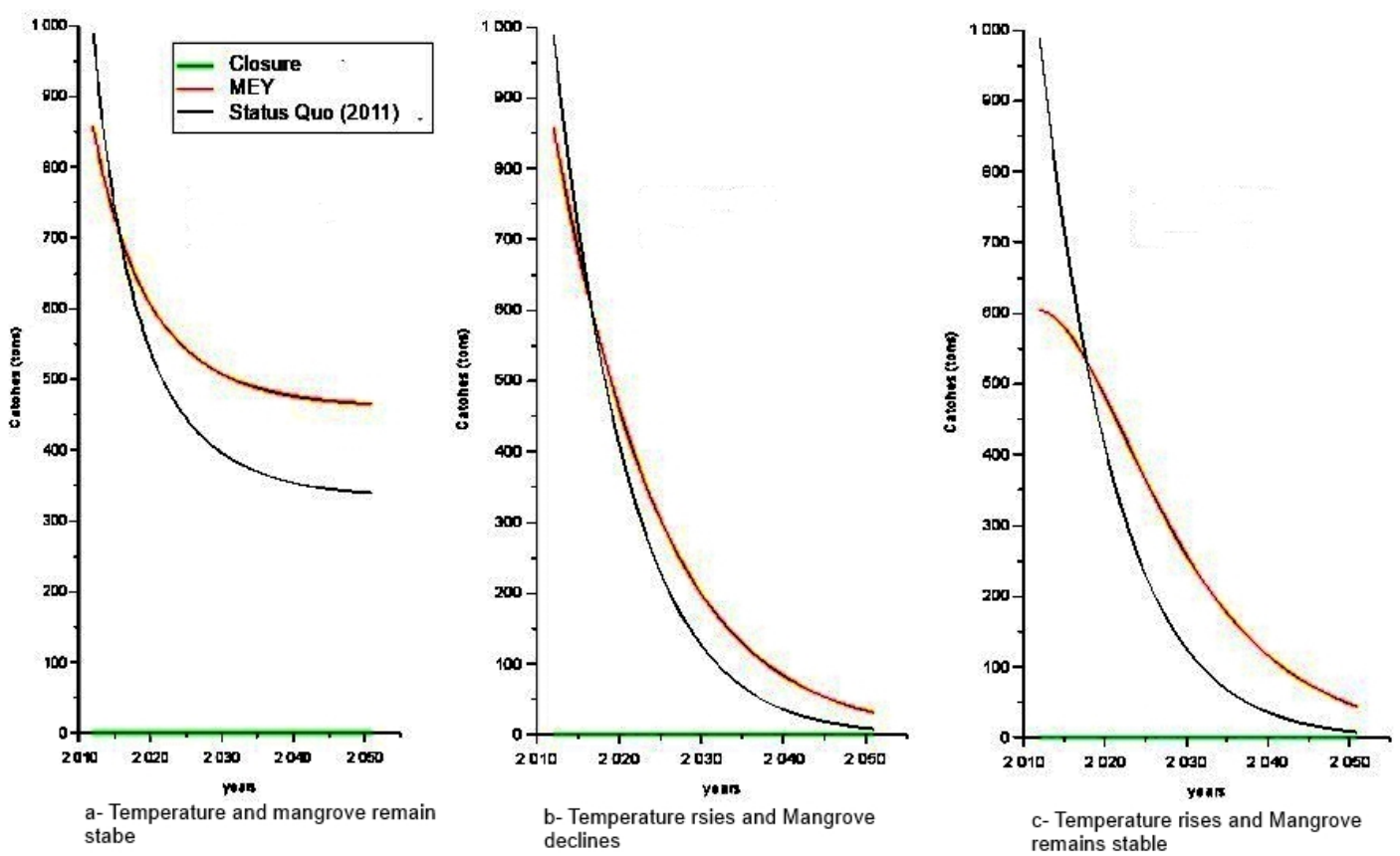

Figure 5: Trajectories for catch catch under mangrove fluctuations and climatic scenarios: a- Temperature and Mangrove remain stable, b- Temperature rises and Mangrove declines, c- Temperature rises and Mangrove remains stable, andunder fishing strategies: Closure, MEY and Status Quo 

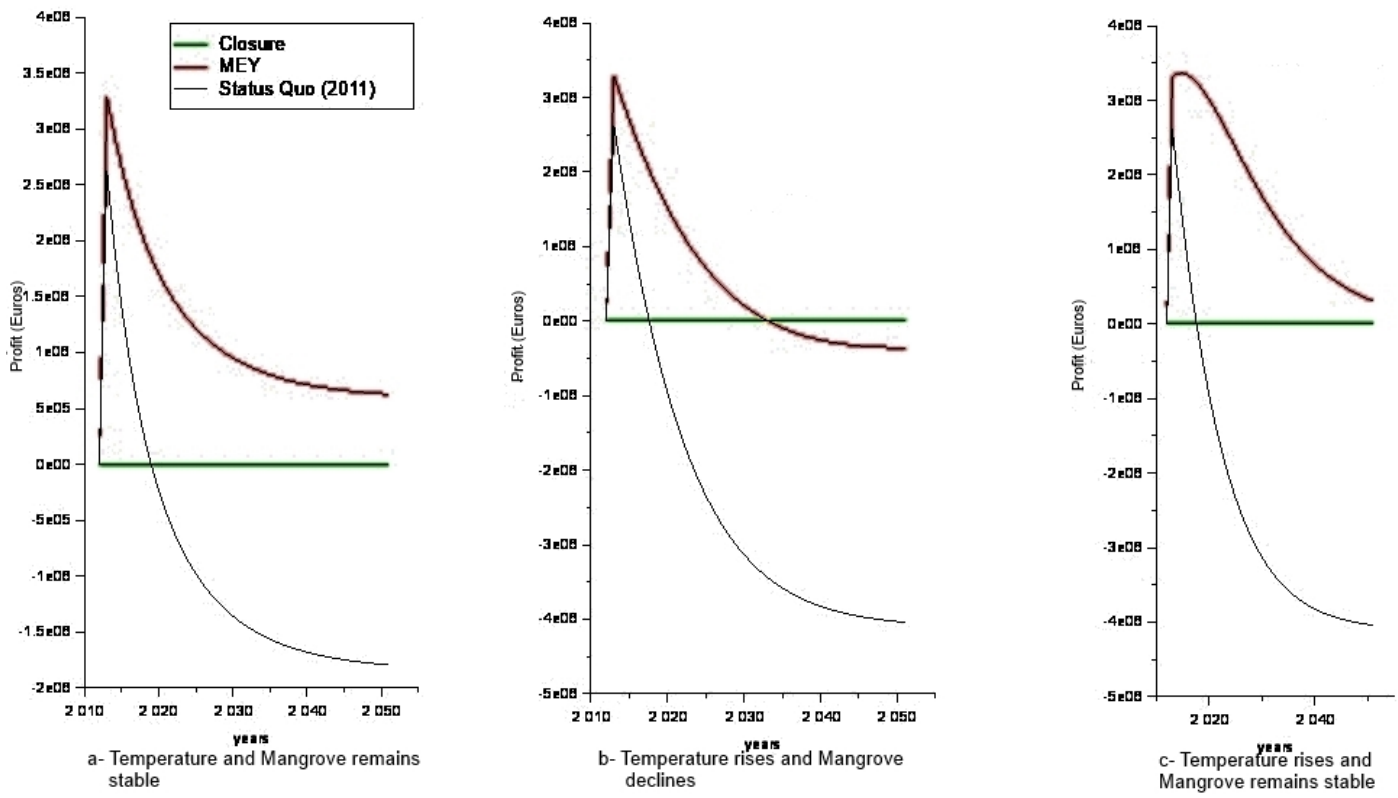

Figure 6: Trajectories for profit under mangrove fluctuations and climatic scenarios: aTemperature and Mangrove remain stable, b- Temperature rises and Mangrove declines, c- Temperature rises and Mangrove remains stable, and under fishing strategies: Closure, MEY and Status Quo 


\subsection{Economic gains of the MEY fishing strategy}

Mangroves provide services that increase the economic productivity/stability of local communities. Figure 7 shows that a decline in mangrove surface will result in profit losses for FGSF. The annual economic losses in profit due to decline in mangrove surface range at least between 1 to 3 million if mangrove surface keeps declining at $1 \%$ per year. The biggest loss could be recorded around 2023 if the mangrove followed the same trend (about 3 million ).

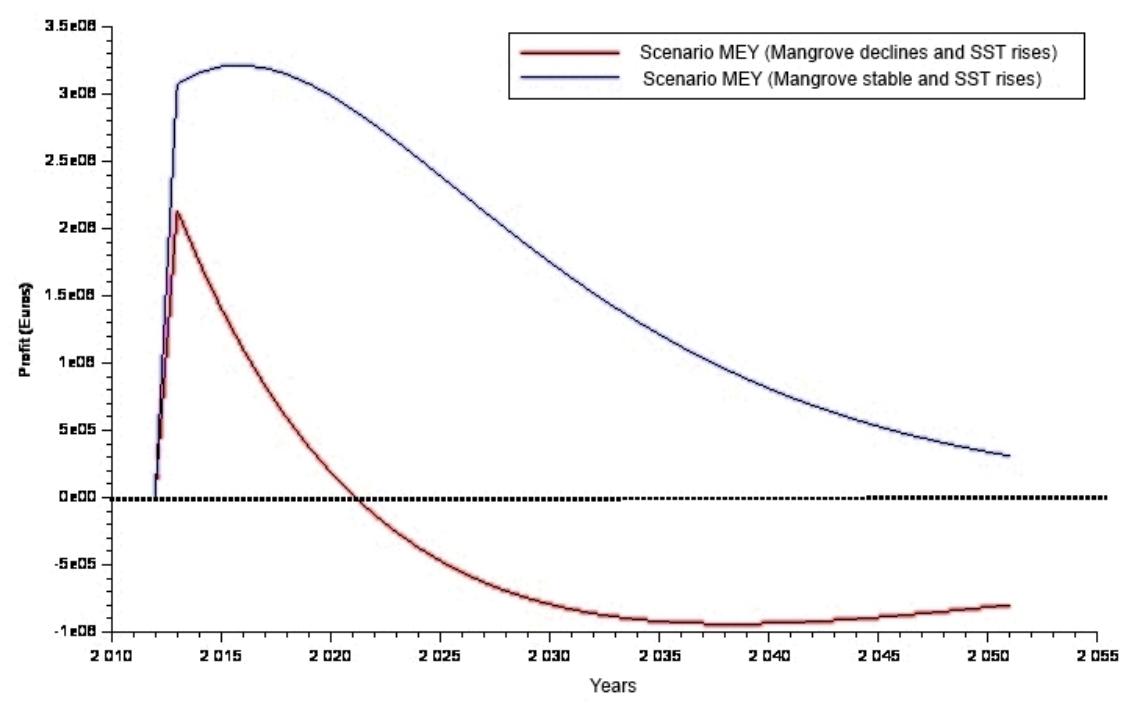

Figure 7: Economic gains of the MEY fishing strategy with respect to scenarios: bTemperature rises and Mangrove declines, c- Temperature rises and Mangrove remains stable

\section{Discussion}

Our results indicate that SST might be the strongest driver of the future evolution of the FGSF due to its effect on shrimps habitat and physiology. Notably, recent works on the characterization of the habitat of Farfantepenaeus subtilis have shown that the optimal surface temperature observed within the distribution area of the species lies between $27.07^{\circ} \mathrm{C}$ and $28.32^{\circ} \mathrm{C}$ (Kaschner et al., 2013). Between 1995 and 2011, the sea surface temperatures in French Guiana have twice exceeded the maximum optimal value (in 1998, and 2005). This suggests that the biological function (growth, maturation, 
survival) may have been degraded at these occasions. Taking into account the projection period considered in this paper, the maximum optimal value is exceeded continuously in 2019. Hence, the decrease in the stock predicted here, seems to be consistent with the previous statement. Unfortunately, the negative effect of the SST rise on the stock seems to be stronger than the positive effect of the effort and harvest fall, even if the mangrove surface is protected. This seems to confirm the starting hypothesis of the present paper, i.e. the predominance of environmental phenomena over economic factors per se.

Despite the fact that our study focused solely on the effect of temperature changes, several others global warming factors including sea level rise, increased storminess and altered precipitation regime are also threats impacting coastal and marine communities (Ward et al., 2016). Climate change effects are expected to vary importantly between regions and precipitations are projected to increase in the north part of South America. Despite this, the concomitant effect of deforestation and global changes in the Amazon basin is still unclear (Bagley et al., 2014; Ward et al., 2016).

Fishing is not the only parameter influencing stock, a wide number of social, economic and environmental factors may cause the collapse of the stock of a fishery (Mason, 2002; Hutchings and Reynolds, 2004). Environmental changes and fishing pressure result in large fluctuations of aquatic species compositions (Cury et al., 2003). Changes in communities compositions and species interactions may lead to a strong decline in biomass of one species, for example, increase in predation pressure or diminution of preys (Lilly et al., 2000; Estes et al., 2011). Additional biological threats include the competition processes between species belonging to the same functional group or with new invasive species (Cury et al., 2003; Dukes and Mooney, 2004).

Furthermore, according to Equation (5), the observed fall in harvest may be due to a decrease either in the stock or in the effort level, or both. However, Table 2 indicates that in the FGSF, the elasticity of harvest with respect to the stock is 0.95 , whereas the elasticity of harvest with respect to effort is 0.16 . Hence, harvest appears to be mostly sensitive to the stock. This suggests that the rise in SST, through its strong direct effect (see Table 1), plays the main role in the fall of harvest. The fall in the shrimp stock and harvest is quite surprising, since according to Bjørndal et al. (1993), harvesting costs depend on the stock-output elasticity. Since the French Guiana shrimp production appears to be very sensitive to changes in the stock, the fall in the latter, by strongly increasing harvesting costs, should constitute an economic brake in its depletion process, which is apparently not the case. Despite the fall in fishing effort observed in the past two decades, the stock continued to decrease. This suggests that the negative impact of SST rise might be stronger than the positive effect of economic brakes. We therefore expect that, in the future, global warming will lead to a total collapse of the shrimp stock and the economic sector that depends on it. However the mangrove could be a source of resilience in front of rises in temperature for better conservation of the stock.

Nevertheless, despite the low effort level, the whole shrimp biomass strongly de- 
creased between 1995 and 2011 (Lampert, 2011). The French Guiana fishing might be indeed negatively affected by environmental changes e.g. SST. However mangrove surface seems to play a role in the mitigation of the effects of global warming on the FGSF. Mangroves can naturally mitigate global warming consequences and increase the ecosystem resilience by absorbing and reorganizing the effects of stress (Gilman et al., 2008). Despite their large thermal admittance due to their wet substrate, mangroves are important cooler elements in coastal areas (Bin, 2016). Maintaining the mangrove surface can mitigate the negative effects of global warming.

There is a real danger that mangroves will disappear from many of the coastal areas in the near future (Duke et al., 2007). Losses are occurring in almost every mangrove forests worldwide. Significant effort must be instigated for the conservation of mangroves to avoid the loss of an essential ecosystem service. Mangroves provide also several highly valued ecosystem services, including coastal protection, erosion control, water purification, maintenance of fisheries, and carbon sequestration (Barbier, 2016). Barbier (2007) assigns a value to these mangrove ecosystem services in Thailand, and compares the net economic returns per hectare to shrimp farming, and the value of mangrove services. Thus mangrove benefits are significant, and should not be ignored in future mangrove land management decisions.

\section{Conclusion}

This paper quantifies the economic benefits of mangrove preservation for the FGSF in a global warming context. A bio-economic model that explicitly integrates the sea surface temperature and the mangrove surface in the natural growth function of the stock is used to analyze the future effects of both phenomena. The parameters of the model are set such that the model statistically fits observed values and allows for undertaking simulations within three distinct scenarios regarding the evolution of the SST of local waters and the mangrove.

Our results strongly suggest that global warming may have a major negative impact on the economic evolution of the FGSF and that local mangrove contributes to mitigate its consequences. Along the same lines, Lopes et al. (2018) show how shrimp productivity is affected by climate change in Brazilian waters. Similarly, de Lange (2013) explains how shrimp fisheries are indeed strongly influenced by environmental factors worldwide. Our study shows that global warming might lead to the collapse of the FGSF in the long run, and that this phenomenon will probably be exacerbated by worldwide mangrove surface expected declines (Duke et al., 2007). The most catastrophic strategy, corresponding to the Status Quo position, might imply negative profits even before 2020, independently of the retained scenario. Only the closure and the MEY strategies allow for positive but very low stock and profit levels. On the one hand, after a definitive closure of the fishery, the stock would rebuild but such a radical decision would be detrimental to 
the French Guiana economy. On the other hand, the bio-economic management based on MEY, (i.e. when temperature rises and mangrove remains stable) would preserve the profitability of the fishery, at least until 2050. However, the MEY strategy would probably not lead to a sufficient conservation of the stock in the long run.

The study developed in this paper confirms that the struggle of fishery stocks against climate change, in particular against global warming, needs to be considered for the sustainable fisheries management. Our paper explains also how to take SST and mangrove surface into account in ecological economic dynamic modelling. Institutional arrangements need to support adaptive management to face global warming risks (Ogier et al., 2016). This is particularly true for tropical fisheries since tropical species generally live close to their thermal limits and have little possibility to move in colder areas. Our analysis thus confirms the need for adopting an ecosystem based management approach, which systematically integrates environmental drivers (such as those related to global warming) to account for the impact of the latter on the stocks' growth and their economic performances.

Acknowledgments: This work has been carried out with financial support from the Belmont Forum through its funding of the SEAVIEW network (ANR-14-JPF1-0003) as well as from the VOGUE, ECOPE, ACOST (PIG CNRS), OYAMAR (FEDER) and ACROSS (ANR-14-CE03-0001) research projects. We would like to thank Dr Morgana Tagliarolo for her helpful comments about biological aspects of the model and interpretations, and Anna Le Joncour for her helpful comments. 


\section{Appendix}

In this section, we present the data collected by Ifremer and used in the present study, estimation details of all other growth functions that do not fit them and some details of the numerical computations.

\subsection{Data set}

In this appendix, Table 3 describes historical data collected by Ifremer for the FGSF, SST and mangrove surface over the period 1995-2011. Biomass, catches and effort decrease simultaneously while SST rises in the same period. The mangrove surface decreases between 1995 and 1998 and increases over 1999-2011 period.

Table 3: Data collected by Ifremer for the French Guiana shrimp fishery over the period 1995-2011, SST and mangrove surface

\begin{tabular}{lccccc}
\hline \hline Year & Biomass (tons) & Total catches (tons) & Effort (days of fishing) & Sea surface temperature $\left({ }^{\circ} c\right)$ & Mangrove $\left(\mathrm{Km}^{2}\right)$ \\
1995 & 10120 & 4010 & 15,723 & 27.87 & 461 \\
1996 & 10303 & 4323 & 17,116 & 27.86 & 457 \\
1997 & 10409 & 3984 & 16,992 & 27.66 & 451 \\
1998 & 9739 & 3940 & 16,320 & 28.43 & 454 \\
1999 & 8765 & 3495 & 16,013 & 27.94 & 458 \\
2000 & 6302 & 2572 & 14,764 & 27.80 & 459 \\
2001 & 6809 & 2651 & 14,026 & 27.67 & 463 \\
2002 & 8120 & 3043 & 13,058 & 27.72 & 474 \\
2003 & 9110 & 3557 & 12,504 & 28.08 & 482 \\
2004 & 8778 & 3325 & 12,550 & 28.16 & 485 \\
2005 & 8026 & 2943 & 9,266 & 28.37 & 485 \\
2006 & 6173 & 2222 & 6,141 & 27.94 & 490 \\
2007 & 6096 & 2369 & 7,278 & 28.02 & 500 \\
2008 & 4000 & 1496 & 4,667 & 28.05 & 503 \\
2009 & 3705 & 1323 & 4,489 & 28.09 & 498 \\
2010 & 3007 & 943 & 4344 & 28.12 & 502 \\
2011 & 2905 & 1037 & 2168 & 28.15 & 519 \\
\hline
\end{tabular}

\subsection{Other growth functions}

In this appendix, Table 4 gives estimation details of all other growth functions that do not fit the data collected. 
Table 4: Estimates of the Cushing, logistic, and Ricker natural growth functions

\begin{tabular}{lccc}
\hline \hline & $X_{\mathrm{t}+1}+h_{t=} a X_{t}^{b+c \theta_{t}+d M_{t}}$ & $X_{t+1}+h_{t} a X_{t}+b X_{t}^{2}+c \theta_{t}+d M_{t}$ & $X_{t+1}+h_{t=} a X_{t} e^{b X_{t}+c \theta_{t}+d M_{t}}$ \\
\hline$a$ & $0.213(0.626)$ & $1.42(0.0376)$ & $-0.45(0.852)$ \\
$\ln (a)$ & $1.79(0.0062)$ & & $1.90(0.009$ \\
$\mathrm{b}$ & $-0.028(0.532)$ & $-2.39 \mathrm{E}-06(0.960)$ & $-5.61 \mathrm{E}-07(0.9191)$ \\
$\mathrm{c}$ & $0.000834(0.0532)$ & $-22.81(0.729)$ & $-0.029(0.0516)$ \\
$\mathrm{d}$ & 0.96 & $27.75(0.501)$ & $0.0005(0.241)$ \\
$\mathrm{R}^{2}$ & 0.95 & 0.93 & 0.96 \\
$\mathrm{R}^{2}$ adjusted & 0.92 & 0.95
\end{tabular}

\subsection{Accuracy of the regression}

In this appendix, we present the production regression accuracy (Figure 8), and the cumulative sum of the recursive residual (Figure 9) to test the parameters constancy. 


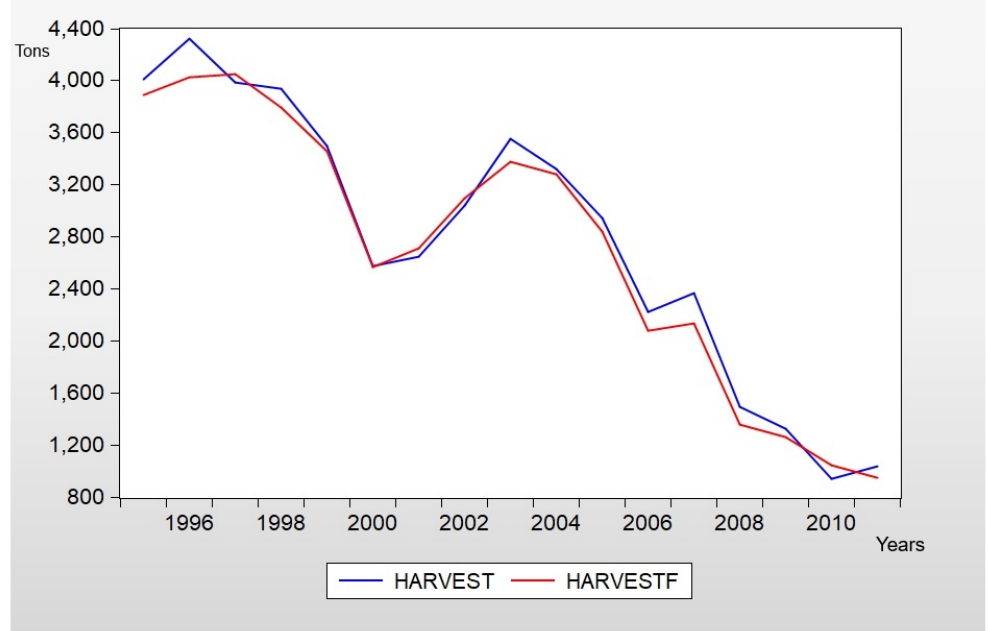

Figure 8: Observed harvest vs predicted harvest

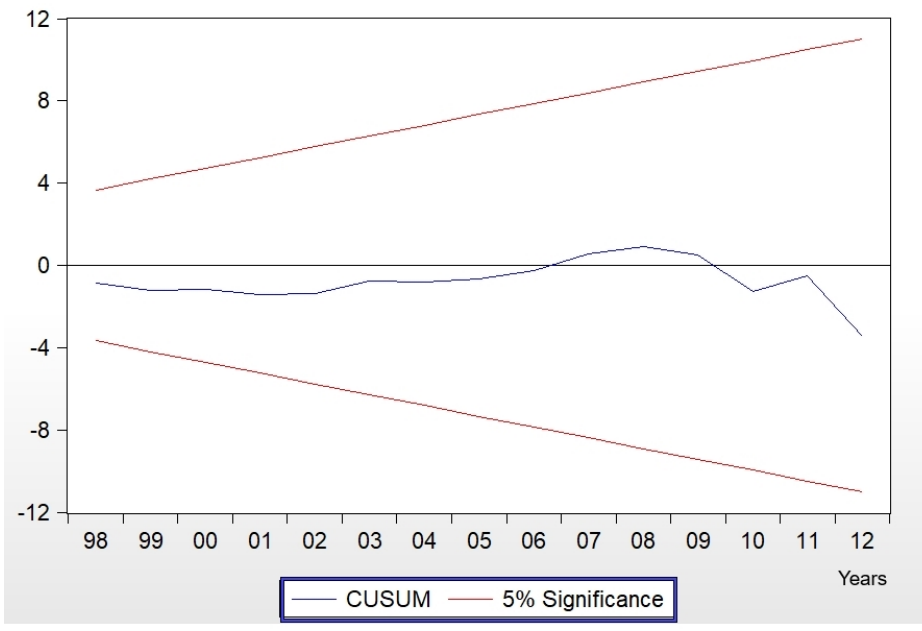

Figure 9: Cumulative Sum of the recursive residuals (CUSUM) 


\section{References}

Anthony, E. J., A. Gardel, N. Gratiot, C. Proisy, M. A. Allison, F. Dolique, and F. Fromard (2010), 'The Amazon-influenced muddy coast of South America: A review of mud-bank-shoreline interactions', Earth-Science Reviews 103: 99-121.

Bagley, J. E., A. R. Desai, K. J. Harding, P. K. Snyder, and J. A. Foley (2014), 'Drought and deforestation: has land cover change influenced recent precipitation extremes in the amazon?' Journal of Climate 27: 345-361.

Barbier, E. B. (2007), 'Valuing ecosystem services as productive inputs', Economic policy 22: $178-229$.

Barbier, E. B. (2016), 'The protective service of mangrove ecosystems: A review of valuation methods', Marine pollution bulletin 109: 676-681.

Bernard, C. (2006), Changement climatique, conséquences potentielles pour la biodiversité ichtyologique et pour la pêche côtière en Guyane française entre 1970 et 2005, Master's thesis, Université La Rochelle.

Bin, O. W. (2016), THE COOLING POTENTIAL OF MANGROVES ON COASTAL URBAN AREAS, Ph.D. thesis.

Bjørndal, T. (1988), 'The optimal management of North Sea herring', Journal of Environmental Economics and Management 15: 9-29.

Bjørndal, T., J. M. Conrad, and K. G. Salvanes (1993), 'Stock size, harvesting costs, and the potential for extinction: the case of sealing', Land Economics : 156-167.

Brander, K. (2010), 'Impacts of climate change on fisheries', Journal of Marine Systems 79: $389-402$.

Brander, K. M. (2007), 'Global fish production and climate change', Proceedings of the National Academy of Sciences 104: 19709-19714.

Brown, R. L., J. Durbin, and J. M. Evans (1975), 'Techniques for testing the constancy of regression relationships over time', Journal of the Royal Statistical Society. Series $B$ (Methodological) : 149-192.

Chen, G., B. Chen, D. Yu, N. F. Tam, Y. Ye, and S. Chen (2016), 'Soil greenhouse gas emissions reduce the contribution of mangrove plants to the atmospheric cooling effect', Environmental Research Letters 11: 124019. 
Cheung, W. W., V. W. Lam, J. L. Sarmiento, K. Kearney, R. Watson, and D. Pauly (2009), 'Projecting global marine biodiversity impacts under climate change scenarios', Fish and Fisheries 10: 235-251.

Clark, C. (1990), Mathematical bioeconomics: the optimal management of renewable resources, A Wiley-Interscience Publication.

Conrad, J. M. (1999), 'The bioeconomics of marine sanctuaries', Journal of Bioeconomics 1: 205-217.

Cury, P., L. Shannon, and Y.-J. Shin (2003), 'The functioning of marine ecosystems: a fisheries perspective', Responsible fisheries in the marine ecosystem : 103-123.

Day Jr, J. W., W. H. Conner, F. Ley-Lou, R. H. Day, and A. M. Navarro (1987), 'The productivity and composition of mangrove forests, Laguna de Terminos, Mexico', Aquatic Botany 27: 267-284.

de Lange, C. (2013), 'Fishery forced to close as shrimp stocks collapse', New Scientist 220: 7 .

De Lara, M. and L. Doyen (2008), Sustainable management of natural resources: mathematical models and methods, Springer Science \& Business Media.

Diop, B., N. Sanz, Y. J. J. Duplan, E. H. M. Guene, F. Blanchard, J.-C. Pereau, and L. Doyen (2018), 'Maximum Economic Yield Fishery Management in the Face of Global Warming', Ecological Economics 154: 52 - 61.

Doyen, L., A. Cissé, S. Gourguet, L. Mouysset, P.-Y. Hardy, C. Béné, F. Blanchard, F. Jiguet, J.-C. Pereau, and O. Thébaud (2013), 'Ecological-economic modelling for the sustainable management of biodiversity', Computational Management Science 10: $353-364$.

Duarte, C. M., I. J. Losada, I. E. Hendriks, I. Mazarrasa, and N. Marbà (2013), 'The role of coastal plant communities for climate change mitigation and adaptation', Nature Climate Change 3: 961.

Duke, N. C., J.-O. Meynecke, S. Dittmann, A. M. Ellison, K. Anger, U. Berger, S. Cannicci, K. Diele, K. C. Ewel, C. D. Field, N. Koedam, S. Y. Lee, C. Marchand, I. Nordhaus, and F. Dahdouh-Guebas (2007), 'A World Without Mangroves?' Science 317: $41-42$.

Dukes, J. S. and H. A. Mooney (2004), 'Disruption of ecosystem processes in western North America by invasive species', Revista chilena de historia natural 77: 411-437. 
Estes, J. A., J. Terborgh, J. S. Brashares, M. E. Power, J. Berger, W. J. Bond, S. R. Carpenter, T. E. Essington, R. D. Holt, J. B. Jackson et al. (2011), 'Trophic downgrading of planet Earth', science 333: 301-306.

FAO (2007), The world's mangroves 1980-2005, Food and Agriculture Organization of the United Nations, FAO Forestry Paper 153, Rome.

Garandeau, C. (2006), Les comptes économiques de la Guyane en 2015. La baisse de l'investissement ralentit la croissance, INSEE Antilles Guyane.

Garza-Gil, M. D. (1998), 'ITQ systems in multifleet fisheries', Environmental and Resource Economics 11: 79-92.

Garza-Gil, M. D., J. Torralba-Cano, and M. M. Varela-Lafuente (2011), 'Evaluating the economic effects of climate change on the European sardine fishery', Regional Environmental Change 11: 87-95.

Gilman, E. L., J. Ellison, N. C. Duke, and C. Field (2008), 'Threats to mangroves from climate change and adaptation options: a review', Aquatic botany 89: 237-250.

Hannesson, R. (2006), 'Sharing the Northeast Arctic cod: possible effects of climate change', Natural Resource Modeling 19: 633-654.

Hutchings, J. A. and J. D. Reynolds (2004), 'Marine fish population collapses: consequences for recovery and extinction risk', AIBS Bulletin 54: 297-309.

Kamien, M. I. and N. L. Schwartz (1991), 'Dynamic optimisation', The calculus of variations and optimal control in economics and management (second edition) North Holland, New York.

Kaschner, K., J. Rius-Barile, K. Kesner-Reyes, C. Garilao, S. Kullander, T. Rees, and R. Froese (2013), 'AquaMaps', Predicted range maps for aquatic species World Wide Web electronic publication, Version 8: 2013.

Keyl, F. and M. Wolff (2008), 'Environmental variability and fisheries: what can models do?' Reviews in Fish Biology and Fisheries 18: 273-299.

Knowler, D. (2002), 'A review of selected bioeconomic models with environmental influences in fisheries', Journal of Bioeconomics 4: 163-181.

Lampert, L. (2011), 'Etude de la crise de la pêche de la crevette en Guyane-Volume 1: Effets de la pêcherie, hypothèses des causes', Archives Ifremer . 
Lehodey, P., J. Alheit, M. Barange, T. Baumgartner, G. Beaugrand, K. Drinkwater, J.-M. Fromentin, S. R. Hare, G. Ottersen, R. I. Perry, C. Roy, C. D. van der Lingen, and F. Werner (2006), 'Climate Variability, Fish, and Fisheries', Journal of Climate 19: $5009-5030$.

Levitus, S., J. I. Antonov, T. P. Boyer, and C. Stephens (2000), 'Warming of the world ocean', Science 287: 2225-2229.

Lilly, G., D. Parsons, and D. Kulka (2000), 'Was the increase in shrimp biomass on the northeast Newfoundland shelf a consequence of a release in predation pressure from cod?' Journal of Northwest Atlantic Fishery Science 27: 45-62.

Lopes, P. F. M., M. G. Pennino, and F. Freire (2018), 'Climate change can reduce shrimp catches in equatorial Brazil', Regional Environmental Change 18: 223-234.

Marchand, C., E. Lallier-Vergès, F. Baltzer, P. Albéric, D. Cossa, and P. Baillif (2006), 'Heavy metals distribution in mangrove sediments along the mobile coastline of French Guiana', Marine Chemistry 98: 1 - 17.

Mason, F. (2002), 'The Newfoundland cod stock collapse: a review and analysis of social factors', Electronic Green Journal 1.

Moss, R. H., J. A. Edmonds, K. A. Hibbard, M. R. Manning, S. K. Rose, D. P. van Vuuren, T. R. Carter, S. Emori, M. Kainuma, T. Kram, G. A. Meehl, J. F. B. Mitchell, N. Nakicenovic, K. Riahi, S. J. Smith, R. J. Stouffer, A. M. Thomson, J. P. Weyant, and T. J. Wilbanks (2010), 'The next generation of scenarios for climate change research and assessment', Nature 463: 747-756.

Nøstbakken, L. (2008), 'Stochastic modelling of the North Sea herring fishery under alternative management regimes', Marine Resource Economics 23: 65-86.

Nunes, A., T. Gesteira, and S. Goddard (1997), 'Food ingestion and assimilation by the Southern brown shrimp Penaeus subtilis under semi-intensive culture in NE Brazil', Aquaculture 149: 121-136.

Ogier, E. M., J. Davidson, P. Fidelman, M. Haward, A. J. Hobday, N. J. Holbrook, E. Hoshino, and G. T. Pecl (2016), 'Fisheries management approaches as platforms for climate change adaptation: Comparing theory and practice in Australian fisheries', Marine Policy 71: 82-93.

Opsomer, J.-D. and J. M. Conrad (1994), 'An open-access analysis of the northern anchovy fishery', Journal of Environmental Economics and Management 27: 21-37. 
Pérez-Castañeda, R. and O. Defeo (2005), 'Growth and mortality of transient shrimp populations (Farfantepenaeus spp.) in a coastal lagoon of Mexico: role of the environment and density-dependence', ICES Journal of Marine Science 62: 14-24.

Sanz, N., B. Diop, F. Blanchard, and L. Lampert (2017), 'On the influence of environmental factors on harvest: the French Guiana shrimp fishery paradox', Environmental Economics and Policy Studies 19: 233-247.

Serafy, J. E., G. S. Shideler, R. J. Araújo, and I. Nagelkerken (2015), 'Mangroves enhance reef fish abundance at the Caribbean regional scale', PloS one 10: e0142022.

Silva, E., N. Calazans, M. Soares, R. Soares, and S. Peixoto (2010), 'Effect of salinity on survival, growth, food consumption and haemolymph osmolality of the pink shrimp Farfantepenaeus subtilis (Pérez-Farfante, 1967)', Aquaculture 306: 352-356.

Smith, R. W. (1986), Exclusive Economic Zone Claims: An Analysis and Primary Documents, Martinus Nijhoff Publishers.

Spalding, M. (2010), World atlas of mangroves, Routledge.

Stock, C. A., M. A. Alexander, N. A. Bond, K. M. Brander, W. W. Cheung, E. N. Curchitser, T. L. Delworth, J. P. Dunne, S. M. Griffies, M. A. Haltuch, J. A. Hare, A. B. Hollowed, P. Lehodey, S. A. Levin, J. S. Link, K. A. Rose, R. R. Rykaczewski, J. L. Sarmiento, R. J. Stouffer, F. B. Schwing, G. A. Vecchi, and F. E. Werner (2011), 'On the use of IPCC-class models to assess the impact of climate on Living Marine Resources', Progress in Oceanography 88: $1-27$.

Thébaud, O., L. Doyen, J. Innes, M. Lample, C. Macher, S. Mahévas, C. Mullon, B. Planque, M. Quaas, T. Smith, and Y. Vermard (2014), 'Building ecologicaleconomic models and scenarios of marine resource systems: Workshop report', Marine Policy 43: 382 - 386 .

Thomson, A. M., K. V. Calvin, S. J. Smith, G. P. Kyle, A. Volke, P. Patel, S. DelgadoArias, B. Bond-Lamberty, M. A. Wise, L. E. Clarke et al. (2011), 'RCP4. 5: a pathway for stabilization of radiative forcing by 2100', Climatic change 109: 77 .

Walcker, R., E. J. Anthony, C. Cassou, R. C. Aller, A. Gardel, C. Proisy, J.-M. Martinez, and F. Fromard (2015), 'Fluctuations in the extent of mangroves driven by multidecadal changes in North Atlantic waves', Journal of biogeography 42: 2209-2219.

Ward, R. D., D. A. Friess, R. H. Day, and R. A. MacKenzie (2016), 'Impacts of climate change on mangrove ecosystems: a region by region overview', Ecosystem Health and Sustainability 2: e01211. 